\title{
Design of a platform for assessing multimedia advertising content consumption with mobile devices validation
}

\author{
López, J.P.; Sánchez, F.; Valhondo, J.; Jiménez, D.
}

\author{
González-Miranda, S.; Bourg, L.
}

\begin{abstract}
Multimedia advertising content needs to be assessed before campaign to assure its future success. Content consumption techniques are used to identify user's interest through a determined content, but it needs effective validation. This paper describes the design of a two-fold analysis of video consumption implemented on EPSIS platform to measure users' interest. The platform consists in a web interface for video visualization which executes an algorithm for automatic validation of user's consumption, and a mobile application which subsequently enables users to assess the video content previously visualized. The video portfolio featured in our platform corresponds to advertising content and social media, which has special characteristics of length and complete meaning and is easier to be assessed than longer contents such as documentary or films. After developing subjective tests with a collection of observers, the mobile application allows to demonstrate the validation of the algorithm. The platform succeeds in validation of advertising contents reducing time and cost derived from the evaluation process.
\end{abstract}

Keywords- advertising content, audiovisual consumption, mobile application, user's interest, video platform

\section{INTRODUCTION}

$\mathrm{T}$ HE impact derived from an advertising campaign depends on a collection of factors, especially when video contents are associated to it. The involvement of the purchaser in the advertising message may change perceptions of the product in the process of shifting the relative salience of attitudes [1]. Factors having an impact on the formation of satisfaction in the audience have been described in literature [2], among the most common: motivational, attitudinal, technological and behavioral or performance. Those factors should be especially considered within advertisement content.

Latest research in the field of audiovisual consumption analyses systems with implicit information. Content-based recommendations may estimate the user's interest offering an approach for digital multimedia content personalization based on user profile information [3]. Choice on advertisement affects to the video attention and user's interest [4].

Previous work collected in [5] shew the importance of recommendation in audiovisual consumption. Also, the work in [6] fully demonstrated the ratification of video quality through mobile devices applications. The platform developed offers a powerful tool for this purpose, in which, the validation of the process goes beyond other implementations.

In the context of developing efficient tools based on new technologies which save cost and time, EPSIS platform is an effective solution for predicting the impact of any campaign by performing subjective tests with real observers while assuring the quality of the contents created for that purpose.

\section{OBJECTIVES AND PLATFORM DESCRIPTION}

Automatically determining video interest by analyzing user's consumption is a powerful tool for predicting the quality of multimedia contents. Algorithms need to be validated with external tools, such as applications implemented in mobile devices.

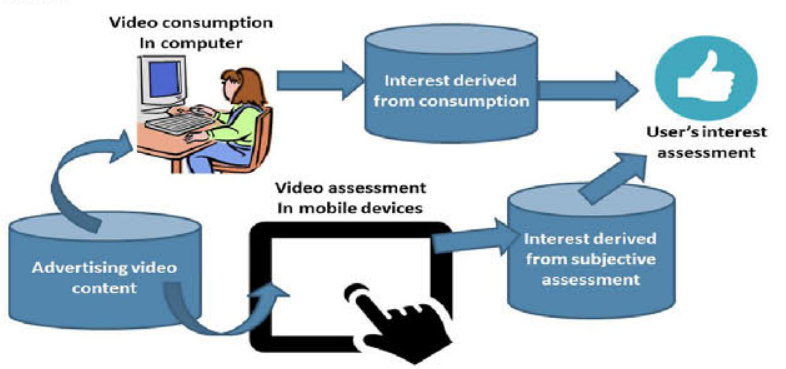

Fig. 1. EPSIS platform description

EPSIS platform prototype described in Fig. 1 presents the twofold analysis of the information obtained: 1) estimation of interest derived from consumption through web services and 2) interest derived from subjective assessment through mobile devices. The platform, which offers an estimation of user's real interest is mainly composed by three basic elements:

First, a web interface for automatically estimating the interest inference, which is developed in HTML5 technologies, for presenting to the user a collection of video sequences to assess. Secondly, a mobile application developed and tested in tablets and smartphones as a complement to the previously obtained inferred interest. The purpose of this application is the validation the correctness of assessment results. Finally, a 
PHP backend with a MySQL database acts as an interface of communication between the first two elements. Finally, the inference results can be shared within social networks (see Diseminacion / EPSIS Demo videos at [8]).

\section{INFERRED INTEREST AND REAL CONTENT INTEREST}

The approach based on Computer browser platform + Automatic user's consumption + Inferred interest has been derived from previous works described in [7]. Through a mobile application the subjective interest measurement calculates three parameters obtained through the answers of users to a collection of questions.

TABLE 1. QUESTIONS FOR OBTAINING USERS' INTEREST IN APPLICATION

\begin{tabular}{|c|c|}
\hline Questions included in the application & Parameters \\
\hline $\begin{array}{c}\text { Question about the global quality of the video } \\
\text { previously observed by the user. }\end{array}$ & Global Explicit \\
Interest $\left(\boldsymbol{q}_{1}\right)$ \\
\hline $\begin{array}{c}\text { Question about observers' interest in the theme } \\
\text { determined by the consumed video sequence }\end{array}$ & $\begin{array}{c}\text { Thematic Explicit } \\
\text { Interest }\left(\boldsymbol{q}_{2}\right)\end{array}$ \\
\hline $\begin{array}{c}\text { Question about visual and esthetic quality in the } \\
\text { consumed video sequence }\end{array}$ & $\begin{array}{c}\text { Esthetic Explicit } \\
\text { Interest }\left(\boldsymbol{q}_{3}\right)\end{array}$ \\
\hline
\end{tabular}

The user's real interest is calculated as a function of the previous calculated parameters. Obtaining a number in the MOS scale from 1 (low interest) to 5 (high interest).

$$
\text { Int }=\alpha_{1} f\left(i_{\text {inf }}\right)+\alpha_{2} f\left(q_{1}, q_{2}, q_{3}\right)
$$

Where Int represents the user's real interest as a function of the parameters calculated through both ways: the inferred interest derived from consumption $f\left(i_{\text {inf }}\right)$ and $f\left(q_{1}, q_{2}, q_{3}\right)$ the interest derived from subjective assessment $\alpha_{1}$ and $\alpha_{2}$ are constants dependent from the content analyzed.

\section{RESULTS DERIVED FROM PLATFORM TESTS}

Tests were developed with a collection of different thematic sequences. Users had free interaction over ten video sequences, Table 2 contains samples of the tests.

TABLE 2. EXAMPLE OF USER'S INTEREST DETECTION

\begin{tabular}{|c|c|c|c|c|c|}
\hline $\begin{array}{c}\text { User } \\
\text { Id }\end{array}$ & Content Title & $\begin{array}{c}\text { Inferred } \\
\text { Interest }\end{array}$ & $\begin{array}{c}\text { Global } \\
\text { Explicit } \\
\text { Interest }\end{array}$ & $\begin{array}{c}\text { Thematic } \\
\text { Explicit } \\
\text { Interest }\end{array}$ & $\begin{array}{c}\text { Esthetic } \\
\text { Explicit } \\
\text { Interest }\end{array}$ \\
\hline 88 & Gender Violence & 3 & 3 & 2 & 3 \\
\hline 94 & News: 4G & 1 & 5 & 5 & 5 \\
\hline 94 & Life learning & 5 & 1 & 1 & 1 \\
\hline 110 & $\begin{array}{c}\text { Professional } \\
\text { Formation }\end{array}$ & 5 & 5 & 4 & 5 \\
\hline 110 & News: 4G & 1 & 1 & 2 & 1 \\
\hline 110 & $\begin{array}{c}\text { Sustainable } \\
\text { Aquaculture }\end{array}$ & 2 & 3 & 1 & 1 \\
\hline
\end{tabular}

Three different situations have been identified where twofold validation plays a key role in detection of false success. First situation (row indicated in blue) is when user's inferred interest is high (5) due to full video view. Likewise, the subjective assessment reveals user's interest. Second situation (row indicated in green) reveals low user's real interest (1) through a combination of low interest inferred from not playing full video and low evaluation. Finally, the third case (row indicated in red) shows a contradiction between two parameters revealing that user's real interest is not corresponding to consumption. "User Id" is a randomly assigned number for user's identification.

\section{CONCLUSIONS}

The proposed system for EPSIS project contributes to the improvement of other proposals for audiovisual consumption analysis, as demonstrated with results obtained in the phase of interest inference. The information obtained after testing including varied database is satisfactory for automatically modelling interest inference analyzing users' interaction. Advertisement audiovisual content parametrization allows the personalization of video sequences based on recommendation algorithms.

On the other hand, first advances in this research field are focused in the interest inference of audiovisual consumption, which is not equal for different scenarios. Additionally to the qualitative parameters improvement, a probabilistic model is able to consider redundancy for content analysis, allowing obtaining user's trends in personal consumption and the importance of contextual and environmental factors.

In short period of time, the results are very satisfactory. Nonetheless, applying inference algorithm to analyze video consumption is not enough for assuring proper results. This fact is a consequence of the environment conditions which implies the unreliability in random observer's interaction. The validation process through mobile devices allows a quick and easy evaluation of the collected data. With two-fold analysis data, advertisement videos can be properly assessed with reliable results in the EPSIS platform.

\section{ACKNOWLEDGMENT}

The work developed between Universidad Politécnica de Madrid and Planet Media was performed in the framework of project IPT-2011-1393-430000 EPSIS: Entertainment and segmented advertisement in immersive environments [8] which is partially funded by the Spanish Ministry of Economy and Competitiveness.

\section{REFERENCES}

[1] Krugman, H. E. (1965). The impact of television advertising: Learning without involvement. Public opinion quarterly, 29(3), 349-356.

[2] Manero, C. B., Uceda, E. G., \& Serrano, V. O. (2013). Understanding the consumption of television programming: development and validation of a structural model for quality, satisfaction and audience behaviour. International Journal of Marketing Studies, 5(1), p142.

[3] Weiß, D., Scheuerer, J., Wenleder, M., Erk, A., Gülbahar, M., \& Linnhoff-Popien, C. (2008, September). A user profile-based personalization system for digital multimedia content. In Proceedings of the 3rd international conference on Digital Interactive Media in Entertainment and Arts (pp. 281-288). ACM.

[4] Nettelhorst, S. C., \& Brannon, L. A. (2012). The effect of advertisement choice on attention. Computers in Human Behavior, 28(2), 683-687.

[5] Sanchez, F., Alduan, M., Alvarez, F., Menéndez, J. M., \& Baez, O. (2012). Recommender system for sport videos based on user audiovisual consumption. Multimedia, IEEE Transactions on, 14(6), 1546-1557.

[6] Lopez, J. P., Slanina, M., Arnaiz, L., \& Menéndez, J. M. (2013, July). Subjective quality assessment in scalable video for measuring impact over device adaptation. In EUROCON, 2013 IEEE (pp. 162-169). IEEE. Generales

[7] Sanchez, F., Alduan, M., Alvarez, F., Menéndez, J. M., \& Baez, O. (2012). Recommender system for sport videos based on user audiovisual consumption. Multimedia, IEEE Transactions on, 14(6), 1546-1557.

[8] EPSIS project website. http://www.epsis.planetmedia.es/ 